\title{
Los retos del IFE rumbo a las elecciones de 2012
}

\section{Francisco Javier Guerrero Aguirre*}

\section{Sumario:}

I. El proceso electoral 2008-2009

II. Estadísticas en materia sancionatoria del proceso de 2009

III. Resoluciones importantes de la Sala Superior, que llamamos casos emblemáticos

V. Intervención del IFE en elecciones estatales

VI. Retos para el proceso electoral de 2012

VII. La experiencia de 2006

VIII. Propaganda en Internet

IX. Confianza en la democracia

* Consejero Electoral del IFE.

D. R. (c) 2012. Universidad Nacional Autónoma de México-Instituto de Investigaciones Jurídicas. 
Es importante compartir en esta prestigiosa revista especializada en temas jurídicos, el punto de vista de un miembro del Consejo General, al que preocupa desde luego que la labor del Instituto Federal Electoral (IFE) en estas elecciones sea profesional, transparente y por supuesto eficiente.

Las elecciones del próximo 1o. de julio, tienen características jurídicas y políticas que las convierten en inéditas:

- La de 2012 será la primera elección presidencial en que se aplicará el nuevo modelo de comunicación política que se estableció no sin resistencias, en la Reforma Electoral Constitucional de 2007.

- Será la primera elección presidencial en la que el IFE desplegará todas sus facultades sancionatorias, para hacer respetar las múltiples reglas que surgieron de la reforma de 2007-2008.

Es por estas características únicas de ésta elección y por la complejidad de su realización que, considero que al IFE le esperan grandes retos en los próximos meses, quiero destacar, en este espacio los cinco que considero más relevantes al inicio del proceso federal: 1) el de organización y capacitación; 2) el que tiene que ver con la aplicación del modelo constitucional de comunicación política; 3 ) el voto de mexicanos en el extranjero; 4) el uso de Internet, y 5) la confianza ciudadana en el IFE y en la democracia como sistema.

Para poder solventar estos retos, el IFE cuenta con experiencias previas de gran valor, que ayudarán a resolver los supuestos que se presenten en el proceso electoral federal, las cuales son el Proceso Federal Electoral de 2009 y la intervención del IFE en las elecciones estatales de 2010 y 2011.

\section{El proceso electoral 2008-2009}

El Instituto Federal Electoral tuvo la encomienda de instrumentar las modificaciones constitucionales y legales aprobadas por los legisladores en 2007 y 2008, a través de la creación y aprobación de diversos reglamentos internos, de acuerdo a lo ordenado por el artículo noveno transitorio del código electoral, publicado en el Diario Oficial de la Federación el 14 de enero de 2008. 
De esta forma se aprobaron 21 nuevos reglamentos y 3 normas reglamentarias, en 4 distintas sesiones del Consejo General celebradas en 2008; se emitieron 171 acuerdos en materia de radio y televisión y se fiscalizaron 4887 informes de precampaña.

El Consejo General del IFE sesionó en 88 ocasiones durante este proceso, en comparación a las 32 sesiones del proceso 2005-2006.

Se expidieron 8 millones de credenciales de elector, de diciembre de 2008 a diciembre de 2009.

Para la integración de las mesas directivas de casilla, el 29 de enero de 2009, el Consejo General llevó a cabo el sorteo del mes del calendario que junto con el que siguió en su orden, fueron tomados como base para la insaculación de los ciudadanos que integrarían las mesas directivas de casilla, quedando sorteado el mes de julio y por subsecuente agosto. Mientras, el 2 de marzo en el Consejo General se sorteó la letra del alfabeto, a fin de obtener el apellido paterno de los ciudadanos que integrarían las mesas directivas de casilla, que en el caso concreto, fue la letra " $Z$ ".

Para capacitar a los funcionarios que integrarían las mesas directivas de casilla, se procedió a realizar el procedimiento de contratación de los supervisores electorales y capacitadores asistentes electorales, de manera general, mediante las etapas de reclutamiento, selección, contratación, capacitación y evaluación.

La convocatoria del Instituto tuvo una amplia participación, los resultados de la evaluación curricular arrojaron que se aceptaron 156983 expedientes, lo que representó $537.61 \%$ respecto al total de plazas a contratar. Los aspirantes que obtuvieron las más altas calificaciones en la evaluación integral, fueron contratados de acuerdo al número de plazas autorizadas para sendos cargos en cada distrito. En total, en el país se contrataron 3481 supervisores electorales y 25719 capacitadores electorales.

La primera insaculación, tomando en cuenta el sorteo arrojó la cantidad de 7837565 ciudadanos insaculados, lo que representó 10.42\% de la lista nominal de electores del país, integrada en ese momento por 75153807 ciudadanos inscritos. En julio de 2012, tendremos poco más de 80 millones de ciudadanos inscritos.

De los 7837565 ciudadanos insaculados, $51.47 \%$ correspondió a mujeres y $48.53 \%$ a hombres.

El total de ciudadanos que conformaron el listado de aptos ascendió a 2354067. 
Al término del procedimiento de segunda insaculación, el sistema reportó la cantidad de 987352 funcionarios designados, lo que representó $41.94 \%$ de los ciudadanos capacitados aptos y $99.99 \%$ de funcionarios requeridos.

De los 987352 funcionarios designados 139181 tuvieron el cargo de presidentes (14.10\%), 145753 fueron secretarios (14.76\%), 139181 primeros escrutadores (14.10\%), 139179 segundos escrutadores (14.10\%) y 424058 suplentes generales (42.95\%); de éstos 423691 eran hombres (42.91\%) y 563661 mujeres (57.09\%). La sociedad respondió al IFE y estuvo a la altura de las circunstancias.

Se instalaron 139181 casillas, y se recibieron 34560344 votos, de una lista nominal de 77470785 ciudadanos, votos nulos fueron $1867729 .{ }^{1}$

El PRI obtuvo 12,702,481; el PAN 9,679,435 y el PRD 4,217,885. En general fue un resultado aceptado y las incidencias fueron mínimas. La sociedad reconoció la labor del IFE en la organización electoral, los partidos políticos reconocieron al IFE y se pudo transitar en muy buenos términos con los nuevos actores regulados, en especial aunque con dificultades al inicio del proceso, con los medios masivos de comunicación, al final del proceso reportaron cumplimientos de transmisión de pauta arriba del 90\%, en términos generales.

Al día de hoy, para el Proceso Electoral Federal 2011-2012, se tiene considerado instalar 147,905 casillas básicas, contiguas y extraordinarias, se imprimirán $83,877,408$ boletas electorales, para presidente de la República y el mismo número para senadores y diputados federales, así como 300 mil actas de la jornada electoral, no tenemos todavía todas las cifras que corresponden al proceso electoral federal que inicia, sin embargo, los datos anteriores nos dan una idea de cuál es la situación que tendremos en cuanto a ciudadanos convocados y en su momento capacitados por el IFE.

Recordemos que es precisamente la organización de las elecciones federales, la primera razón de ser del IFE y que es esta labor la que ha sido reconocida dentro y fuera del país por elecciones anteriores, ya que la instrumentación de los números que acabamos de citar del proceso federal anterior, nos da una idea de cómo debe funcionar la estructura del instituto en el país para poder lograr concretar con éxi-

1 Informe General sobre la Implementación de la Reforma Electoral durante el Proceso 2008-2009. 
to la instalación y funcionamiento de las miles de casillas que se instalarán en el país. Es claro que la estructura local y distrital del IFE, son una pieza clave para el éxito de los comicios.

Es gracias a la cada vez más intensa competencia por el voto, entre los involucrados en el proceso electoral, y las demandas de certeza en los resultados, que permanentemente se tienen por parte de la sociedad, que a estas funciones primigenias de organización y capacitación electoral, se han sumado nuevas atribuciones tendientes a que las elecciones no sólo sean legítimas y confiables, sino también equitativas, recordemos la frase del ex presidente Zedillo que reconoció precisamente que su elección había sido legítima pero no equitativa.

La búsqueda de la equidad en la contienda es lo que en 2007 le generó al IFE 53 nuevas atribuciones, entre las que se encuentran que asuma funciones sancionatorias no sólo para los directamente involucrados en la contienda, como son candidatos y partidos políticos, sino aquellos sujetos o poderes que inciden también o incidieron en los procesos electorales pasados, tal es el caso de los gobiernos federal y estatales, mediante el uso de la propaganda gubernamental, los medios de comunicación por la influencia y penetración que tienen en la sociedad y por el excesivo gasto que se hacía en la propaganda política de las campañas, la Iglesia, y en general las personas físicas y morales que ahora no pueden comprar espacios en medios de comunicación para influir a favor o en contra de tal o cual candidato. Esto último es, precisamente, lo que permitió calificar a la reforma como violatoria de la libre expresión, argumento que como sabemos la Suprema Corte desestimó.

El ejercicio de estas atribuciones sancionatorias se ha dado desde 2008 y en especial durante el proceso electoral federal de 2009, el rostro ciudadano del IFE ahora ha adquirido un matiz de autoridad administrativa sancionadora, que para algunos es ya la primera instancia de una actividad jurisdiccional electoral. Estas atribuciones, sin embargo, a diferencia de otras autoridades sancionadoras, se ejercen de cara a los sujetos regulados, es decir a los partidos políticos representados en el Consejo General y por supuesto de cara a la Nación, tratándose del tema de medios de comunicación, es claro que el debate inicia en el Consejo General, pero en muchos casos continúa en los medios de comunicación. 


\section{Estadísticas en materia sancionatoria del proceso de 2009}

En 2009, se presentaron 1026 quejas y denuncias para Procedimiento Especial Sancionador (PES), atendidas en todo el país: 663 en las juntas y los consejos distritales y 363 por el Consejo General; 192 radicadas como procedimientos especiales sancionadores.

2100 consejeros distritales actuaron como jueces en las resoluciones de controversias presentadas.

De las 192 quejas radicadas como procedimientos especiales sancionadores, se conocieron en razón de los siguientes motivos principales:

41 por presunta promoción personalizada de servidores públicos, en supuesta violación al artículo 134, párrafo octavo (o séptimo y octavo) de la Constitución; 34 por denigración y calumnia, en la propaganda electoral; 27 por actos anticipados de campaña; 23 por incumplimiento en los pautados ordenados por el Instituto; 23 por la presunta contratación indebida de spots en radio y/o televisión, y 20 por difusión de propaganda gubernamental en etapa de campaña electoral.

El IFE ha sido acompañado de forma oportuna y eficiente por el Tribunal Federal Electoral del Poder Judicial de la Federación, y se han establecido diversos criterios por el Tribunal que orientan la función administrativa y la sancionadora del Instituto.

\section{Resoluciones importantes de la Sala Superior, que llamamos casos emblemáticos}

La Sala Superior ha realizado interpretaciones, sin precedentes previos, de disposiciones nuevas que se tuvieron que aplicar.

1. Respecto de la mención de los programas sociales dentro de la propaganda de un partido político, en el SUP-RAP-23-2009, se consideró valido que el Partido Acción Nacional hiciera mención de ellos en su propaganda, así como del Presidente de la República, por considerarlo como un activo del partido político y como parte del debate propio de la contienda. 
2. En cuanto a la inserción de cortinillas previas a la transmisión correcta de la pauta, que sucedió al inicio de las campañas políticas, se consideró que era una manipulación de la misma, en el SUPRAP-59-2009 y por lo tanto fue una conducta ilegal.

3. Se consideró también, respecto de los spots, que contienen extractos de informes de los legisladores de un partido político en la etapa de inter-campañas, que no trasgreden la normatividad electoral, aun cuando hayan sido pagados con recursos privados, y en los mismos aparezca el logotipo del instituto político al que pertenecen, ya que es una obligación constitucional de los legisladores informar sobre sus actuaciones, en el SUP-RAP-75-2009. No obstante estar prohibidos en etapa de campañas.

4. En relación con los grupos parlamentarios en la jurisprudencia 10/2009 se consideró que las prohibiciones que rigen para la propaganda institucional o gubernamental, aplican igualmente para los legisladores del Congreso de la Unión, como grupos parlamentarios. Comprende la prohibición a cualquier ente público, quedando incluidos en el supuesto tanto los legisladores en lo individual como en grupos parlamentarios, pues si bien no constituyen por sí mismos el Poder Legislativo, sí forman parte de él y no se pueden desvincular de la cámara a la que pertenecen.

5. Por lo que respecta a la propaganda gubernamental, la jurisprudencia 11/2009, considera que la difusión de propaganda gubernamental que realicen en los medios de comunicación social los poderes públicos federales, estatales o municipales, los órganos de gobierno del Distrito Federal, sus delegaciones y, en general, todos los servidores, funcionarios y entes públicos, se encuentra limitada por razones de contenido y temporalidad.

En cuanto al contenido, en ningún caso podrá ser de carácter electoral, esto es, debe de abstenerse de estar dirigida a influir en las preferencias electorales de los ciudadanos a favor o en contra de partidos políticos o de candidatos a cargos de elección popular. Por lo que hace a la temporalidad, no puede difundirse en el entorno de un proceso electoral, durante los periodos que comprenden las campañas electorales, y en el periodo de reflexión, conformado por los tres días previos al de la elección, y hasta el final de la jornada electoral, salvo en 
los casos previstos expresamente en el artículo 41, base III, apartado $\mathrm{C}$, in fine, de la carta magna.

6. Respecto de propaganda denigratoria se definieron criterios de sanción amplios, llegando a pronunciarse la Sala Superior, en el sentido de que por disposición constitucional, las campañas deben de ser propositivas. En el SUP-RAP-81-2009, que resolvió el asunto conocido como "Sopa de Letras", se ordenó sancionar el hecho tanto por propaganda denigratoria en contra del Partido Revolucionario Institucional, como por acto anticipado de campaña.

7. De la imparcialidad en el uso de recursos públicos, se consideró que la promoción personal de un presidente municipal, en la página de Internet del gobierno municipal, transgrede el artículo 134 constitucional, en el SUP-RAP-43-2009, ya que la misma en ese caso concreto, se consideró que sí tenía como finalidad promoverse políticamente.

8. Se definió también que la publicidad en televisión, mediante spots de revistas que difundan elementos de propaganda electoral, durante las campañas, debía estimarse como prohibida, y se ordenó sancionar incluso al entonces presidente del PAN, en el SUP-RAP-198-2009, por haberse ubicado en este supuesto con la promoción de la revista Poder y negocios, así como al Partido Verde, por haber hecho lo mismo en las revistas TV y Novelas y Cambio. ${ }^{2}$

\section{Administración del tiempo del Estado en el proceso electoral 2009}

El Instituto Federal Electoral en el Proceso Electoral Federal 2009, ordenó en total la pauta de más de 30 millones de spots, para partidos políticos y para las autoridades electorales en el país, en el proceso 20011-2012, consideramos que serán aproximadamente 40 millones.

Número de impactos en el proceso electoral 2009:

- Por estación y canal: diarios 96.

- Para Partidos: 36 precampañas, 82 campañas.

${ }^{2}$ www.trife.gob.mx, consulta de sentencias. 
- Por día a nivel nacional: 196128.

- Por día para partidos en época de campañas: 167526.

- Para partidos políticos en todas las campañas federales: 14201538 (60 días).

- Total en época electoral, todo el proceso electoral octubre-julio (153 días): 33456384.

La labor del monitoreo de la pauta es una función también nueva para el Instituto.

- Fueron monitoreados por el IFE durante el proceso electoral 384 canales de televisión, 511 estaciones de FM y 579 estaciones de AM.

La labor de pautado y monitoreo asignada al IFE representa, como vemos, un compromiso muy sensible e importante, que impacta al interior del Instituto y al exterior del mismo, los medios de comunicación son factores determinantes para el éxito de la comunicación política entre los actores del proceso y por la tanto para la elección federal.

Esta función que se ha llamado de coadministradora de los tiempos del Estado, se realiza por parte del IFE, también para procesos locales.

\section{Intervención del IFE en elecciones estatales}

La Suprema Corte de Justicia de la Nación al resolver la acción de inconstitucionalidad número 33/2009 y sus acumuladas 34/2009 y $35 / 2009,{ }^{3}$ determinó la competencia del IFE en procesos electorales locales.

El IFE interviene en los procesos electorales locales, en virtud de las disposiciones legales y con base también en los convenios suscritos, en tres aspectos principales:

- Administración de los tiempos del Estado en radio y televisión, para los partidos políticos y autoridades electorales.

- Apoyo con las funciones del Registro Federal de Electores.

3 Publicada en el Diario Oficial de la Federación el 4 de septiembre de 2009. 
- Resolver solicitudes de medidas cautelares sobre propaganda en radio y televisión que se considera prohibida, en términos de poder ser denigratoria o calumniosa o bien por ser propaganda gubernamental difundida durante las campañas electorales.

Respecto de la pauta ordenada, en las 12 entidades donde hubo elecciones locales y se eligió gobernador en 2010, se ordenó el pautado a 565 emisoras en estas entidades, mientras que en Chiapas, Baja California, en las pasadas elecciones de Yucatán, y las elecciones extraordinarias en dos municipios de Coahuila, se pautaron a 173 emisoras. En total en todas las elecciones locales de 2010 se ha ordenó pautar a 738 emisoras de radio y televisión.

En total estamos hablando de 1856633 promocionales que se distribuyeron en las entidades donde hubo elecciones, de los cuales 1516123 promocionales correspondieron a promocionales en las entidades donde hubo cambio de gobernador.

Respecto de las quejas por propaganda indebida de acuerdo a la Constitución, destaca de la experiencia de los procesos de 2010, la resolución 119/2010 de la Sala Superior, relacionada con la falta cometida por el presidente de la República, por haber difundido propaganda gubernamental los días 15 y 30 de junio y 1o. de julio de 2010, en los estados con campañas electorales, se dijo por el Tribunal, al asumir plena jurisdicción en este asunto que el presidente violó el artículo 41 constitucional, pero no es posible sancionarlo, de acuerdo a su interpretación del artículo 108 constitucional.

Asimismo, en la Comisión de Quejas y Denuncias, se ordenaron medidas cautelares por promocionales con contenido negativo, en las campañas de Puebla, Veracruz, Oaxaca, Zacatecas, Durango, Sinaloa y Quintana Roo.

\section{Retos para el proceso electoral de 2012}

\section{Organización electoral}

El IFE revisó en junio y julio, el marco normativo reglamentario, a efecto de actualizar las 21 disposiciones reglamentarias que se aprobaron en 2009, y poder enfrentar todas las tareas relacionadas a la organización y capacitación electoral con éxito. 
Para el proceso de 2012 se insacularán, seguramente, a cerca de 8 millones de ciudadanos y serán nombrados de manera eventual funcionarios de casillas, más de un millón de ellos.

El IFE se prepara para poder instalar y equipar con los materiales correspondientes a más de 140000 casillas electorales en el país, pautar durante el proceso electoral cerca de 35 millones de spots para partidos políticos y autoridades electorales, mandar a imprimir cerca de 80 millones de boletas electorales y conocer seguramente una cantidad importante de quejas y denuncias electorales. Permítanme referirme a algunos de estos retos.

\section{Renovación de las credenciales para votar "03"}

De acuerdo al artículo 200, párrafo 4 del Cofipe, la credencial para votar tendrá una vigencia de 10 años, contados a partir de su emisión, a cuyo término el ciudadano deberá solicitar una nueva credencial.

El artículo octavo transitorio del Código, establece que para la aplicación de la vigencia de las credenciales “03” y “09" se deberá tomar en cuenta lo siguiente:

Para el cumplimiento de lo establecido en el párrafo $4^{\circ}$ del artículo 200 del código de la materia, las credenciales para votar que tengan como último recuadro el "03" para el marcaje del año de la elección federal, podrán ser utilizadas por sus titulares para ejercer el derecho de voto hasta la elección del año 2009. A partir del día siguiente a la celebración de la jornada electoral respectiva, los ciudadanos en este supuesto, deberán acudir al módulo de atención ciudadana con la finalidad de actualizar sus datos en el Padrón Electoral.

El 7 de julio de 2010, el Consejo General emitió el Acuerdo CG224/2010, por medio del cual se aprobó que la vigencia de las credenciales “03" concluya el 31 de diciembre de 2010, como medio de identificación y como identificación para votar.

El Consejo General estableció en dicho acuerdo que esta disposición general tendría la excepción de vigencia en las entidades en donde habrá elecciones para gobernador, diputados y ayuntamientos en este año, en Baja California Sur, Coahuila, Guerrero, Edomex, Michoacán y Nayarit y para ayuntamientos nada más en Hidalgo. 
Se aprobó también que las credenciales cuyo último recuadro sea "09" se puedan utilizar en las elecciones federales del 1o. de julio de 2012.

Se están tomando las medidas necesarias para lograr la renovación de cerca de 7.5 millones de credenciales “03", a tiempo y que estos ciudadanos puedan votar en 2012.

\section{Retos relacionados con el modelo de comunicación política}

Los medios de comunicación tienen una influencia considerable en el electorado y por ello la necesidad de distribuir con equidad el derecho de los partidos políticos de acceder a los mismos como una prerrogativa.

A decir del español Francisco Paniagua, el proceso de comunicación política resulta imprescindible para que el electorado tenga toda la información posible a la hora de acudir a su cita electoral. Este proceso no sólo es insustituible, sino que además legitima el sistema democrático.

Estamos hablando de un derecho ciudadano de carácter político y es el de tener la suficiente información, para decidir el sentido del voto, libre, universal, secreto e informado, el IFE debe cuidar que así sea, que las campañas sean de información para el elector, dentro de los márgenes legales, que tenemos para ordenar el pautado de spots de los partidos políticos en campañas.

El IFE debe cuidar que las conductas contrarias a las normas de propaganda, no tengan impacto en la equidad en la contienda, actualmente los tiempos para ordenar la suspensión de una propaganda prohibida mediante medidas cautelares no permiten que se evite el daño al principio de equidad, por lo menos por unos cinco días que tarda la notificación. Será necesario hacer conciencia para que esta propaganda no se suba al aire.

- Se debe de cuidar el cumplimiento puntual de la transmisión de la pauta.

- Debemos insistir en que los contenidos de los mensajes sean de propuesta y generen debate, se debe evitar el mensaje denigratorio. 


\section{Voto de los mexicanos en el extranjero}

Es hasta el 30 de junio de 2005, que se publica en el Diario Oficial de la Federación el Decreto del Congreso de la Unión que contiene las reformas al código electoral, modificando el artículo 250 y adicionando un libro especial el Sexto, que comprende los artículos del 273 al 300. Lo que permite la votación de mexicanos en el extranjero por primera vez en la elección presidencial de 2006.

El Marco Jurídico aprobado, determinó principalmente:

- La emisión del voto en el extranjero mediante el modelo postal.

- Los requisitos y plazos para que un ciudadano residente en el extranjero pueda inscribirse en el listado nominal especial.

- Los procedimientos que debe realizar el IFE para instrumentarlo.

- El universo de migrantes con posibilidad de votar residentes en Estados Unidos debe de ser aproximadamente de 13 millones de mexicanos, más de 10\% del Padrón Electoral.

\section{La experiencia de 2006}

Según el informe especial de la Unidad de Asuntos Internacionales del IFE, para la elección presidencial de 2006 se recibieron 40876 solicitudes de inscripción en la lista nominal de electores residentes en el extranjero, y se emitieron únicamente 32632 votos, cabe decir que la expectativa de potenciales electores se había calculado en 4.2 millones de ciudadanos con posibilidad de votar.

De los factores que influyeron en la baja participación, destacan los siguientes:

- El poco tiempo para instrumentar los mecanismos de envío de solicitudes.

- Poco tiempo para la difusión de la campaña en Estados Unidos, se llegó a contratar un plan de medios y se difundieron spots en Estados Unidos únicamente del 19 al 28 de abril de 2005.

Se detectaron aspectos legales que restringieron también la participación, como fueron: 
1) Se requiere credencial de elector, cuando ésta sólo se expide en territorio nacional y se solicitan documentos probatorios que seguramente muchos ciudadanos residentes en el extranjero no tienen.

2) Se requiere un comprobante de domicilio en Estados Unidos, el cual la mayoría de los mexicanos en el extranjero no tiene o evita darlo por razones de seguridad.

3) Se obliga al envío por correo postal certificado de la solicitud lo cual implica un costo para el ciudadano.

4) Se prohíbe la propaganda política en Estados Unidos.

La experiencia de 2006 dejó lecciones importantes que habrá que valorar, lo que es un hecho es que es un tema pendiente con los connacionales y un compromiso del Estado mexicano.

Nuestro país está marcado por la migración y en este sentido considero que debemos ir a la vanguardia en cuanto a efectividad y mayor extensión de derechos políticos, para migrantes.

El plan para las elecciones de 2012 consiste en una mayor difusión en Estados Unidos, mediante convenios y contratos con Univisión y otras cadenas, mayor compromiso de las representaciones diplomáticas de México y presencia incluso física de personal del IFE en Estados Unidos.

Concretamente se tiene programada una campaña intensa de 15 meses, que incluya redes sociales y portales de Internet, especiales para el voto en el exterior.

\section{Propaganda en Internet}

De manera implícita, de acuerdo a una interpretación amplia del Código Federal de Instituciones y Procedimientos Electorales (Cofipe), se comprende al Internet de la siguiente forma:

El artículo 212 del Cofipe, que se refiere a precampañas, señala:

Se entiende por propaganda de precampaña el conjunto de escritos, publicaciones, imágenes, grabaciones, proyecciones y expresiones que durante el periodo establecido por este Código y el que señale la convocatoria respectiva difunden los precandidatos a candidaturas a cargos de elección popular con el propósito de dar a conocer sus propuestas. 
De acuerdo a esta interpretación la propaganda de los precandidatos está sujeta según lo dispone el artículo 217 del mismo Cofipe, a las normas previstas en el código respecto de actos de campaña y propaganda electoral.

Lo anterior significa que la propaganda que se contrate, por parte de los partidos políticos o candidatos en Internet, se considera dentro de los informes de gastos, para efectos de fiscalización y asimismo está sujeta a los límites en su contenido, que el propio Código señala.

- La propaganda electoral en Internet, en el pasado proceso electoral federal de 2009, estuvo presente, a través de redes sociales, sitios web, correos electrónicos, foros, chats, blogs, prensa en línea y otros.

En el Consejo General del IFE conocimos procedimientos relacionados con propaganda difamatoria, a partidos e instituciones a través de videos en Youtube, en virtud de quejas presentadas por partidos políticos. Fue famoso el video alusivo a Fidel Herrera, que tenía como fondo la canción de la película Rudo y Cursi. Como imaginarán para el IFE no fue fácil procurar la suspensión de la difusión de estos videos, que finalmente se dejaron de transmitir por una cuestión de derechos autorales.

De acuerdo a un análisis que realizó el Tecnológico de Monterrey, de los sitios de los partidos políticos durante las campañas en 2009, se señala que todos tuvieron características similares en su contenido: predominó en los portales el dominio de spots de la campaña en televisión, siguiendo claramente una sola línea de propaganda. Tanto en las páginas del PRI como del PT, los spots oficiales fueron colocados a primera vista y al centro de la pantalla. El PRD, el PAN y Convergencia siguieron la misma línea, aunque ubicaron los spots en otros lugares de la página.

En relación con Youtube se señala que se usó como plataforma mediática para publicar todo lo que los medios tradicionales no permitían, tanto por limitaciones presupuestales como por limitaciones legales. La plataforma se convirtió así en el espacio mediático de lo prohibido y el campo de batalla de una "guerra sucia mediática".

De los 10 videos que comprendió la investigación, siete fueron de campañas negativas en contra del PRI, de los más visitados según el estudio estuvo el denominado "Analiza con nosotros un ajuste de 
cuentas en el PRI" con 73712 visitas, firmado al final con el logo del PAN. El segundo más viso fue "Mundo de caramelo de Felipe Calderón” con 27554 reproducciones. El tercer video más visto fue "El PRI se tambalea” con 26644. Quedó demostrado en este sentido que la autoridad en este proceso, no pudo limitar las expresiones negativas en Youtube.

Aunque tampoco sabemos realmente cuál fue la influencia de estas expresiones en la intención del voto, por último el partido más atacado por los videos obtuvo el mayor número de votos.

Respecto de la influencia de la publicidad en las campañas, permítanme referir que según este estudio del Tecnológico de Monterrey, no parece que los anuncios influyan mucho en la decisión electoral, 74\% considera que tomó poco o nada en cuenta esta publicidad para votar.

$39 \%$ considera que la publicidad de los partidos tuvo como fin criticar a otros partidos y $33 \%$ cree que difundieron sus propuestas $(22 \%$ ambas cosas).

La publicidad que más se recuerda por los entrevistados fue la del PVEM y la del PRD. No hay relación estricta entre mayor pauta en medios y mayor recuerdo entre la población.

Las próximas elecciones federales serán seguramente marcadas por la utilización de las redes sociales y de los sitios web, para poder establecer canales de comunicación entre los candidatos y los ciudadanos y entre los propios ciudadanos para evaluar la oferta política y el comportamiento de los candidatos en las redes. Sería positivo y deseable que las expresiones que se presenten en las redes, superen a los videos negativos y que puedan involucrar realmente a la sociedad en la discusión de fondo, ¿qué ofrecen por candidatos, y esto en qué me beneficia como elector?

\section{Confianza en la democracia}

De acuerdo a la conclusión del Latinobarómetro 2010, la debilidad de lo político y la desconfianza, por su parte, son el talón de Aquiles del proceso de consolidación de la democracia, de acuerdo a este análisis en México 49\% de los entrevistados apoya a la democracia, en comparación con el $42 \%$ en 2009. El país que más la apoya es Venezuela con $84 \%$ y Argentina con $66 \%$. Existe además un bajo nivel de satisfacción 
con la democracia, en México es de $27 \%$, en Latinoamérica el promedio es de 44\%, en Argentina y Venezuela su nivel de satisfacción es de $49 \%$.

La gente cree en la democracia, pero no está satisfecha con su funcionamiento.

Se indagó si los entrevistados creen que importa el partido que gobierna. En una escala de 1 a 5 el promedio de las respuestas fue 4.0.

Esto es una amplia mayoría, refiere que sí hay gran diferencia en torno a qué partido gobierna.

Llama la atención que $58 \%$ de los entrevistados asegura que alguno de los partidos políticos representa razonablemente bien sus puntos de vista. 56\% de los entrevistados simpatiza con algún partido político, $43 \%$ no simpatiza.

Es importante señalar que, según Latinobarómetro 2010, el país más satisfecho con la economía es Uruguay con $54 \%$, el segundo más satisfecho es Chile con $49 \%$ y el tercero es Brasil con $47 \%$. Los menos satisfechos son México con 17\%, Guatemala, El Salvador y Perú con $18 \%$.

Según Consulta Mitofsky, en mayo de 2010, la Suprema Corte cuenta con $21 \%$ de confianza, mientras que el IFE con $18.7 \%$, ambas instituciones se encuentran dentro de las seis que gozan de mayor confianza.

Por ello, el reto será para las instituciones electorales, mejorar la confianza; para los partidos incrementar su nivel de identificación, $y$ para los candidatos hacer campañas publicitarias eficientes.

Creo que las redes sociales y la tecnología de la información pueden ser una herramienta muy útil para lograr una participación ciudadana más activa que pueda evaluar de forma permanente el funcionamiento de la democracia y mejorar los niveles de satisfacción.

Hoy los ciudadanos pueden consultar en línea las propuestas políticas de campaña, los programas de gobierno que registran los partidos políticos en el IFE, antes de iniciar las campañas, y pueden compararlas con las acciones de los gobiernos emanados de esas campañas.

Hoy como nunca gracias a la era digital, es posible que exista una sociedad civil organizada al margen del Estado, que participe para exigir mejores políticas públicas, mejores funcionarios, para premiar o no, con su voto a los partidos políticos o para definir incluso acciones de gobierno para su comunidad. 